\title{
Pembangunan Taman Agrowisata Horti Berbasis Pemberdayaan Masyarakat Di Desa Simpang Empat Kecamatan Simpang Empat Kabupaten Banjar
}

\author{
Samahuddin Muharram ${ }^{1}$, Arif Rahman Hakim ${ }^{2}$,Jamiatul Rahmah ${ }^{3}$, Sayuti Al Ikhwan ${ }^{4}$, Novita ${ }^{5}$, \\ Andika Prayoga ${ }^{6}$, Linda Nur Hafizah ${ }^{7}$, Fery Darmawan , Suhandani ${ }^{8}$, \\ ${ }^{1,2}$ Fakultas Ilmu Sosial dan Ilmu Politik Universitas Lambung Mangkurat, \\ Jl. H. Hassan Basry, Banjarmasin, Indonesia, \\ ${ }^{3,4,5,6,7,8,9}$ Mahasiswa Program Studi Ilmu Pemerintahan, Universitas Lambung Mangkurat, Fakultas Ilmu \\ Sosial dan Ilmu Politik, \\ Jl. H. Hassan Basry, Banjarmasin, Indonesia, \\ *email: Samahuddin.fisip@ulm.ac.id
}

Diajukan

29 Oktober 2021

Keywords:

Sosialisasi

Bencana Banjir

Desa Tangguh Bencana

Pengabdian Masyarakat
Informasi Artikel

Diterima

20 November 2021
Diterbitkan

30 November 2021

\begin{abstract}
At the beginning of the year, high rainfall triggered overflows of river water which, in flooding, one of which was in Sungai Tabuk Village, Simpang Empat District, Banjar Regency. The purpose of this service is to provide knowledge about potential disasters, characteristics, impacts, and cycles of flood disaster management for the village government and the people of Sungai Tabuk Village. The methodology used to provide understanding and increase awareness and improve communication between communities is through the Socialization of Flood Disaster Resilient. The stages in this service activity are the preparation stage, the stage of implementing online socialization and the stage of achieving the target. From this activity, it will increase public understanding and awareness to know the threat of disasters in their area so that they are able to organize and reduce disaster risk to reduce vulnerability to disasters with preparedness and make efforts to prevent and recover post-floods.
\end{abstract}

\begin{abstract}
ABSTRAK
Di awal tahun curah hujan yang tinggi memicu terjadinya luapan air sungai, sehingga mengakibatkan banjir, salah satunya di Desa Sungai Tabuk, Kecamatan Simpang Empat, Kabupaten Banjar. Tujuan Pengabdian adalah untuk memberikan pengetahuan tentang potensi bencana, karakteristik, dampak, dan siklus penanggulangan bencana banjir bagi pemerintah desa dan masyarakat Desa Sungai Tabuk. Metodologi yang digunakan untuk memberikan pemahaman dan meningkatkan kesadaran dan memeperbaiki komunikasi antar masyarakat ini melalui Sosialisasi Tangguh Bencana Banjir. Tahapan pada kegiatan pengabdian ini adalah Tahapan persiapan, tahapan pelaksanaan sosialisasi via online dan tahapan ketercapaian sasaran. Hasil yang diperoleh dalam kegiatan ini, di harapkan meningkatkan pemahaman dan kesadaran masyarakat dalam menghadapi ancaman bencana di wilayahnya, sehingga mampu mengorganisir dan mengurangi risiko bencana untuk mengurangi kerentanan terjadinya bencana dengan kesiapsiagaan serta melakukan upaya-upaya pencegahan dan pemulihan pascabanjir.
\end{abstract}

\section{Copyright and License:}

Authors retain copyright and grant the journal right of first publication with the work simultaneously licensed under a Creative Commons Attribution 4.0 International License that allows others to share the work with an acknowledgment of the work's authorship and initial publication in this journal. 


\section{PENDAHULUAN}

Pariwisata merupakan sebuah kegiatan yang memiliki tujuan untuk menyelenggarakan jasa parawisata, menyediakan dan mengusahakan daya tarik wisata, usaha sarana parawisata dan usaha lainnya yang berkaitan dengan bidang wisata. Pariwisata merupakan salah satu aspek penting sebagai penggerak perekonomian dunia yang mana terbukti mampu memberikan kontribusi terhadap kemakmuran sebuah Negara. Pembangunan pariwisata mampu menggairahkan aktivitas bisnis untuk menghasilkan manfaat sosial, budaya, dan ekonomi yang signifikan bagi suatu Negara. Pembangunan sebuah pariwisata yang telah di rencanakan dengan baik mestinya dapat memberikan sebuah manfaat bagi masyarakat sekitar tempat destinasi tersebut (Utama 2016:1)

Pembangunan Pariwisata di suatu daerah harus dapat mencerminkan peranan masyarakat yang di ikut sertakan dalam proses pembangunan parawisata. Pembangunan Destinasi wisata di suatu daerah memerlukan partisipasi dari seluruh elemen masyarakat untuk mengembangkan objek wisata tersebut sehingga dapat meningkatkan kesejahteraan masyarakat di sekitar tempat wisata. Agrowisata merupakan salah satu bentuk parawisata yang memanfaatkan usaha pertanian (agro) sebagai objek wisata. Dengan tujuan untuk memperluas pengetahuan, pengalaman rekreasi dan juga hubungan usaha dibidang pertanian.

Sutjipta dalam Utama (2016;86) mendefinisikan, Agrowisata merupakan sebuah sistem kegiatan yang terpadu dan terkoordinasi untuk pengembangan parawisata sekaligus pertanian, dalam kaitannya dengan pelestarian lingkungan, peningkatan kesejahteraan masyarakat petani. Sedangkan Menurut Sastrayuda (2010) agrowisata merupakan suatu bentuk rangkaian kegiatan wisata yang memanfaatkan potensi pertanian sebagai objek wisata, baik berupa potensi pemandangan alam kawasan pertaniannya maupun kekhasan dan keanekaragaman aktivitas produksi dan teknologi pertanian serta budaya masyarakat pertaniannya. Agrowisata merupakan salah satu bentuk ekonomi kreatif dalam sector pertanian yang dapat memberikan nilai tambah kepada pelaku usaha agribisnis dalam rangka meningkatkan kesejahteraan petani.

Desa Simpang Empat merupakan salah satu desa di Kabupaten banjar yang memiliki potensi wisata dalam pertanian dan perkebunan, melalui Pembangunan taman agrowisata horti dengan berbasis masyarakat akan memberikan gambaran kepada masyarakat setempat mengenai pembangunan taman tersebut, masyarakat dilibatkan secara aktif dan ini menjadi kesempatan untuk berpartisipasi dalam pembangunan taman agrowisata tersebut sekaligus dapat meningkatkan kesejahterahan masyarakat itu sendiri. Taman tersebut memiliki ukuran dengan luas kurang lebih 13 hektar yang merupakan kombinasi antara tanaman buah, sayur-sayuran dan bunga. Lahan seluas kurang lebih 13 hektar terbagi antara 2 hektar untuk tanaman bunga, lahan 10 hektar sebagai tanaman hortikultura dan luas lahan 1 hektar masih dalam tahap pembersihan.

\section{METODE}

Solusi yang tepat untuk mengatasi permasalahan yang dijelaskan di penduhuluan, adalah dengan menerapkan metode sosialisasi/ pelatihan/ penyuluhan/ pendampingan/ pemetaan wilayah bencana dan lainnya. menurut Mahmud yunus "metode" adalah jalan yang hendak di tempuh seseorang supaya sampai padatujuan tertentu, baik dalam lingkungan maupun dalam kupasan ilmu pengetahuan dan laiinnya Dalam pelaksanaan program kerja mahasiswa sangat memperhatikan perihal protokol kesehatan yang berlaku di masyarakat dan saat berinteraksi dengan narasumber wajib mentaati prokes, mahasiswa juga melaksanakan sosialisasi terkait program kerja dengan pihak pemerintah desa setempat, dan melihat potensi desa, di era sekarang pemanfaatan sosial media sebagai wadah untuk mempromosikan potensi dan tempat wisata yang ada di Desa Simpang Empat kepada masyarakat luar, diharapkan memberikan dampak positif terhadap desa simpang empat.

\section{HASIL DAN PEMBAHASAN}

Dalam mendukung Pembangunan Taman Agrowisata horti berbasis pemberdayaan masyarakat, kegiatan yang dilakukan oleh Mahasiswa Ilmu Pemerintahan FISIP Universitas Lambung Mangkurat adalah melakukan upaya sosialisasi dengan pembuatan Branding Desa melalui konten Audio-visual terkait Taman Agro wisata Horti yang ada di Desa simpang Empat dan di publikasikan melalui salah satu stasiun televisi yaitu TVRI dengan bentuk sebuah berita, selain itu dibuat juga mengenai konten teksual dalam bentuk wikipedia yang berisi deskripsi mengenai taman agrowisata horti tersebut. Adapun Tahapan Kegiatan yang dilakukan sebagai berikan: 


\section{a) Tahapan Persiapan}

Tahap awal pada tahapan persiapan adalah Mahasiswa Ilmu Pemerintahan FISIP melakukan rapat bersama melalui media zoom meeting untuk membahas tentang rencana pembuatan Branding desa melalui konten audio-visual terkait Taman Argowisata Horti yang ada di desa Simpang Empat, sebelum membuat konten audio visual mengenai taman Agrowisata beberapa mahasiswa Ilmu Pemerintahan FISIP melakukan survei pertama ke lokasi taman di desa simpang empat yang akan dilakukan pembuatan Branding desa tersebut, setelah proses pengambilan video dokumentasi mengenai kegiatan pembangunan taman Agrowisata Horti di Desa Simpang Empat dan telah melalui proses editing mengenai video tadi. video tersebut kemudian di publikasikan melalui akun media sosial seperti instagram. Selain itu juga melakukan kerja sama dengan salah satu stasiun televisi (TVRI) untuk dipublikasikan hasil video tadi dalam bentuk berita dengan tujuan mampu membuat Taman Argowisata Horti yang ada di Desa Simpang Empat mampu dikenal baik di dalam desa itu sendiri maupun di luar daerah.

Selain branding desa dalam bentuk konten audio visual, di buat juga branding desa dalam bentuk konten tekstual berupa informasi singkat melalui Wikipedia terkait taman agrowisata horti di desa simpang empat. Tahapan persiapan yang dilakukan menuliskan beberapa daftar pertanyaan yang akan di tanyakan kepada masyarakat dan pemerintah setempat yang mengetahui mengenai pembangunan taman tersebut. Kemudian informasi tersebut dikelola dalam bentuk Wikipedia.

\section{b) Tahapan Pelaksanaan}

Pada tahapan ini dilaksanakannya 2 (dua) program kegiatan di tanggal 27 Agustus 2021 dan tanggal 30 Agustus 2021 yang meliputi:

(1) Konten Audio-Visual, adalah program kerja Video Cinematic yang berisi wawancara dengan pengelola taman dan beberapa shot lahan yang ada di taman Agrowisata Horti.

Dalam kegiatan wawancara ini mahasiswa memiliki tujuan agar mengetahui hal-hal yang berkaitan dengan Taman Agrowisata Horti Desa Simpang Empat.

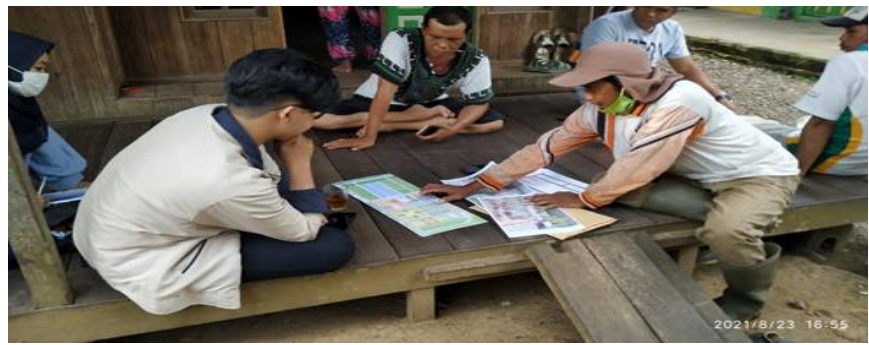

Gambar 1. Wawancara dengan pengelola Taman Agrowisata Horti Desa Simpang Empat

Hasil dari wawancara tersebut adalah mahasiswa mengetahui luas Taman yaitu kurang lebih seluas 13 Hektar merupakan kombinasi antara tanaman buah, sayur dan bunga. Lahan seluas kurang lebih 13 hektar tersebut terbagi antara 2 hektar di khususkan untuk tanaman bunga, 10 hektar untuk tanaman horti dan 1 hektar lahan masih dalam tahap pembersihan.

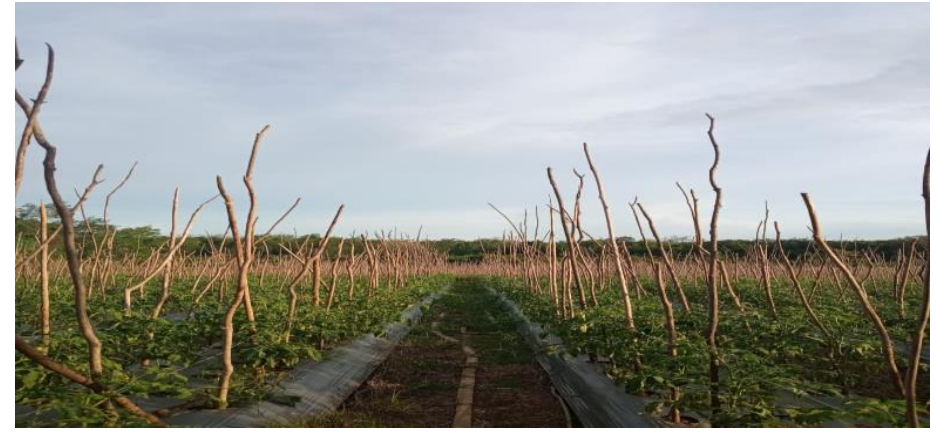

Gambar 2. Area lahan Horti ditaman Agrowisata Horti Desa Simpang Empat 


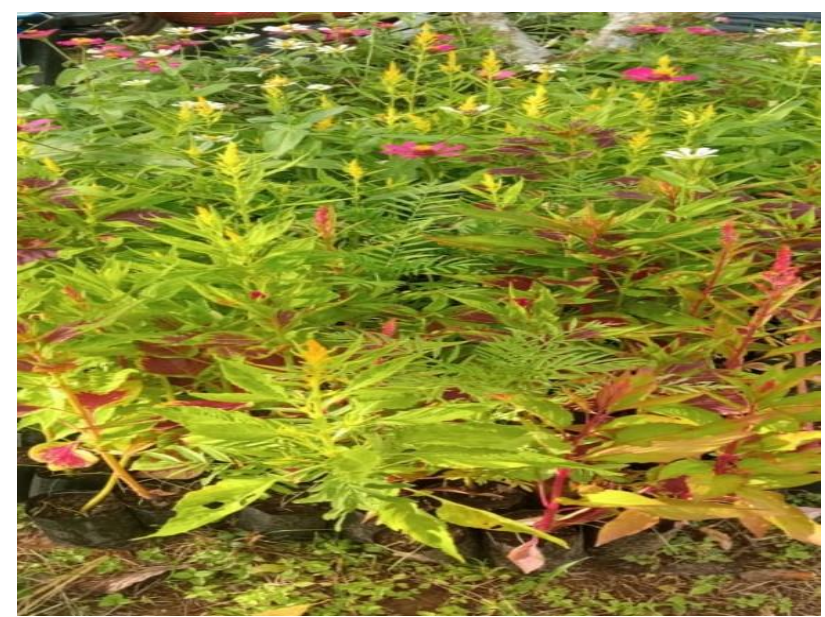

Gambar 3. Tanaman Bunga di Taman Agrowisata Horti Desa Simpang Empat

Setelah mengetahui hal-hal terkait taman Agrowisata Desa Simpang Empat kegiatan selanjutnya yang dilakukan ialah pengambilan foto maupun Video di taman.

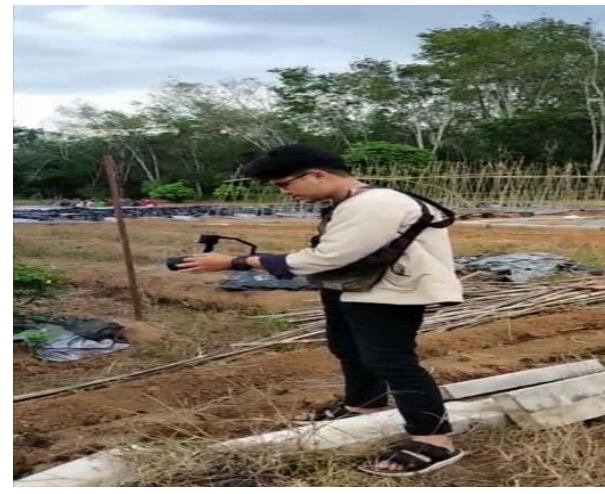

Gambar 4. Pengambilan Foto dan Video di Taman Agrowisata Horti

(2) Konten Tekstual, adalah program kerja merupakan kegiatan pembuatan naskah mengenai taman Agrowisata Horti yang bertujuan untuk keperluan wikipedia agar masyarakat yang ingin mengetahui tentang taman ini dapat mengaksesnya melalui internet dengan mudah. Naskah ini dibuat berdasarkan hasil wawancara dengan pihak pengelola taman. 
Taman Agrowisata Horti

Desa Simpang Empat

Halaman Pembicaraan

Artikel atau bagian artikel ini tidak memiliki
referensi atau sumbert
Pelajari selengkapnya
Taman Argowisata Horti $₫$ adalah taman yang
Kedang di bangun di desa Simpang Empat
provinsi Kalimantan Selatan. Taman Agrowisata
Horti dengan luas lahan kurang lebih 13 hektar
merupakan kombinasi antara tanaman buah,
sayur dan juga bunga. Lahan seluas kurang
lebih 13 hektar tersebut terbagi antara 2 hektar
untuk tanaman bunga, 10 hektar tanaman horti
dan 1 hektar lahan masih dalam tahap
pembersihan.

Taman Agrowisata Horti Desa Simpang Empat

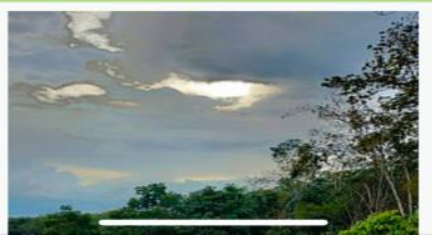

Gambar 5. Wikipedia Taman Agrowisata Horti Desa Simpang Empat

Dalam pelaksanaan program kerja selain bekerjasama dengan pemerintah desa dan masyarakat, mahasiswa juga bekerja sama dengan salah satu stasiun TV yang ada di Kalimantan selatan yang berperan sebagai media publikasi. Tujuan dilaksanakannya program ini adalah untuk mengenalkan taman Agrowisata Horti kepada masyarakat luar yang belum mengenal adanya taman ini.

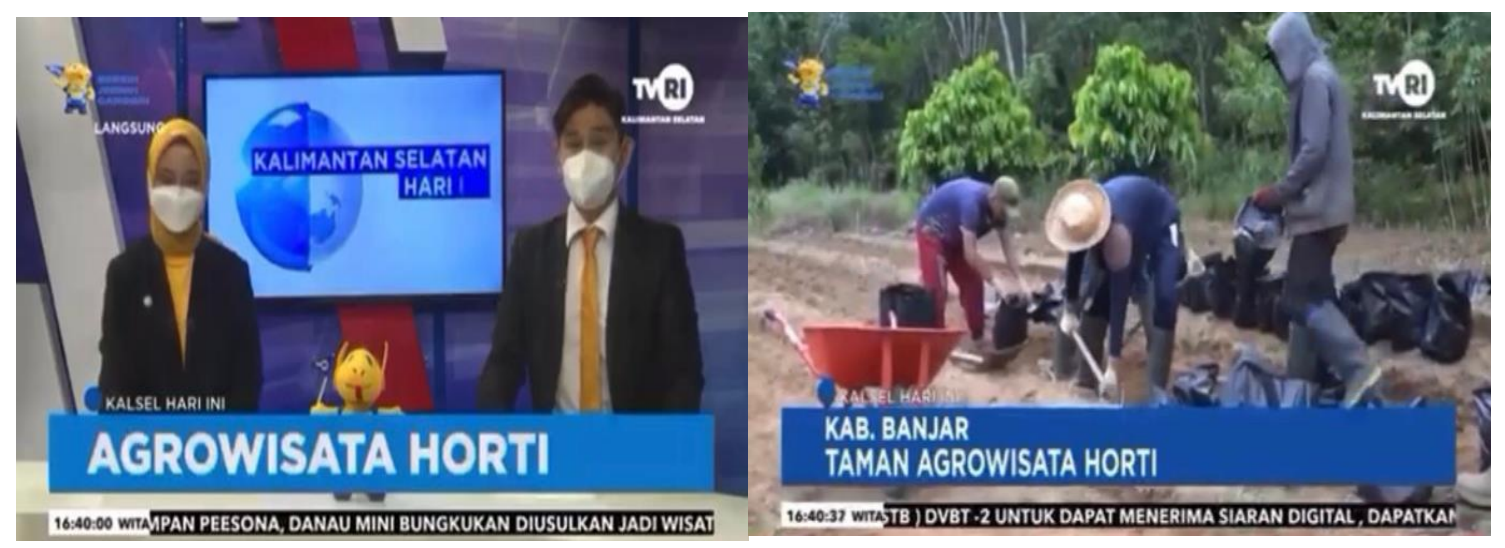

Gambar 6. Tayangan TVRI Kalimantan Selatan mempublikasi Taman Agrowisata Horti Desa Simpang Empat.

\section{c) Ketercapaian Sasaran}

1) Terwujudnya perkembangan Taman Agro Wisata yang di dukung oleh masyarakat perdesaan

2) Terwujudnya pengetahuan, wawasan, sikap dan keterampilan masyarakat perdesaan dalam pengelolaan Taman Agro wisata

3) Tercapainya diversifikasi produk yang mampu menjadi produk wisata unggulan dan meningkatkan ekonomi masyarakat

4) Tersusunya tata cara pengelolaan Taman Agro Wisata yang di dasarkan kepada manajemen pengelolaan yang tepat

5) Tersebarnya lokasi Taman Agro Wisata di setiap desa / kecamatan sebagai salah satu upaya mengembangkan lama tinggal wisatawan, kunjungan wisatawan dan belanja wisatawan. 


\section{KESIMPULAN}

Dalam pelaksanaan ini terdapat beberapa kendala dan keadaan pendukung saat program kerja dijalankan. Seperti terkendalaa oleh waktu yang kurang sesuai dengan kegiataan masing-masing individu warga dan karena faktor cuaca karena ketika saat pelaksanaan selalu hujan. Namun, selain terkendala ada faktor pendukung yang cukup membantu para mahasiswa KKN dalam menyelenggarakan kegiatanya yaitu, dengan adanya dukungan dari aparatur desa dan tersediany sarana prasarana yang ada cukup membantu mahasiswa KKN dalam menjalankan program kerjanya dengan lancar.

\section{UCAPAN TERIMAKASIH}

1. Bapak Akmad Dina, S. Ap selaku kepala desa kantor desa Simpang Empat.

2. Bapak Arkani selaku sekertaris Desa yang dimana telah membantu dalam mengetahui informasi apa-apa saja yang ada di Desa.

3. Bapak Ridwan dan bapak Basri selaku aparatur Desa yang membantu dalam kegiatan KKN kami

4. Pihak TVRI yang telah membantu dalam hal penanyangan di televisi yang berupa program kelompok.

5. Bapak Misrani dan Bapak kirno selaku ketua dan anggota Gabungan Kelompok Tani Kayuh Baimbai

6. Semua pihak yang sudah berpartisipasi dan memberi dukungan baik materi maupun non materi yang tidak dapat penulis sebutkan satu persatu.

\section{REFERENSI}

Utama, I Gusti Bagus Rai. (2016). Agrowisata Sebagai pariwisata Alternatif Indonesia. Yogyakarta: Deepublish.

Pambudi, Haming, Siwi., Sunarto.,Setyono, Prabang. (2018). Strategi pengembangan agrowisata dalam mendukung pembangunan pertanian - studi kasus di desa wisata kaligono (dewi kano) Kecamatan kaligesing kabupaten purworejo. Analisis kebijakan pertanian, Vol. 16 No. 2, Desember 2018:165-184. http://dx.doi.org/10.21082/akp.v16n2 2018.165-184 